\title{
Determination of electrostatic potential distribution by atomic force microscopy (AFM) on model silica and alumina surfaces in aqueous electrolyte solutions
}

\author{
Gulnihal Ozek Yelken, Mehmet Polat* \\ Department of Chemical Engineering, Izmir Institute of Technology, Urla Izmir 35430, Turkey
}

\section{A R T I C L E I N F O}

\section{Article history:}

Received 6 January 2014

Accepted 5 February 2014

Available online 17 February 2014

Keywords:

Atomic force microscopy

Force curve

DLVO theory

Surface potential map

\begin{abstract}
A B S T R A C T
AFM was employed as a physicochemical probe to determine the electrostatic potential distribution quantitatively on selected ideal oxide surfaces (quartz 0001 and sapphire 0001 ) in aqueous media. The force of interaction between a silicon nitride tip and the oxide surface was measured at a given point under well-defined solution conditions. Relevant theories were used to isolate the electrostatic component from the total force of interaction which was then employed to estimate the surface potential at that point. Repeating the procedure on selected locations generated a potential map of the surface. Comparison of these potentials with those obtained from independent electrokinetic measurements confirmed the validity of the approach.
\end{abstract}

(C) 2014 Elsevier B.V. All rights reserved.

\section{Introduction}

Colloidal systems are widely encountered in minerals, ceramics, environment, biology, and pharmaceuticals, cosmetics applications where homogeneity, stability, rheology, plasticity or forming characteristics of the system may be extremely important. Control and manipulation of these properties are directly related to the interactions among the particles which constitute these systems.

The two main components of interparticle interaction are van der Waals and Electrical Double Layer (EDL) forces. Interplay of these two components have been formalized by the DLVO Theory $[1,2]$. Presence of surface active species or structural changes in solution in the vicinity of the particles may lead to secondary interactions which require modifications to these theory [3-5].

van der Waals forces are body forces and can be assumed relatively invariable in a given colloidal dispersion under weak electrolyte conditions with changes in solution chemistry. The EDL forces which arise from spontaneous charging of the solid surfaces in solution, on the other hand, vary greatly with solution chemistry. This is the main reason why electrochemical properties of the colloidal systems are used extensively for stability control.

\footnotetext{
* Corresponding author. Tel.: +90 232750 6693/533 331 7987; fax: +902327506645.

E-mail address: mehmetpolat@iyte.edu.tr (M. Polat).
}

Depending on the solution chemistry, varying magnitudes of positive, negative or neutral surface sites may develop on oxide surfaces. Relative abundance of these sites yield an overall or averaged surface charge. Electrophoretic potential measurements and colloidal titration methods are widely employed to determine quantitatively this charge in a colloidal system. However, these methods yield only an average charge for the surface which leads to assumption that the charge on the surface is homogenously distributed.

It is obvious that use of such an assumption can only approximate the actual mechanism and magnitude of the interactions between surfaces and dissolved species. This shortcoming is simply born from a lack of a better method for determining the actual charge distribution on the surface.

Quantitave force measurement using AFM between two surfaces (a cantilever tip or a colloid particle and the surface of interest) have been widely used in numerous studies [6-29]. In this paper, we will demonstrate that an atomic force microscope (AFM) can be employed as a physico-chemical probe to yield information on the distribution of electrostatic charges on well-defined oxide surfaces. The net force measured by the AFM at a given point on the surface under carefully maintained solution conditions was separated into its component forces. This information was then employed to estimate the surface potential with proper application of relevant theories and methods. Repeating the measurement on multiple points on the surface generated a 3-D distribution of surface potentials. 


\begin{tabular}{|c|c|}
\hline \multicolumn{2}{|c|}{ Nomenclature } \\
\hline$A_{132}$ & $\begin{array}{l}\text { Hamaker constant for particles } 1 \text { and } 2 \text { in medium } \\
3\end{array}$ \\
\hline$b$ & Width of the cantilever (m) \\
\hline BET & Surface area of particle \\
\hline$c$ & Contact point in force measurement $(\mathrm{m})$ \\
\hline$C_{0}$ & Electrolyte concentration of the solution \\
\hline$D$ & Vertical piezo movement in force measurement $(\mathrm{m})$ \\
\hline$d_{50}$ & Median particle size by volume \\
\hline$\underline{d}_{90}$ & Maximum particle size below $90 \%$ by volume \\
\hline$F_{\text {AFM }}$ & AFM measured force $(\mathrm{N})$ \\
\hline$F_{t}$ & Theoretical total force $(\mathrm{N})$ \\
\hline$h$ & Gap length between two surfaces (m) \\
\hline$h$ & $\begin{array}{l}\text { Probe-to-surface separation in force measurement } \\
(h=(D-c)-x ; \mathrm{m})\end{array}$ \\
\hline$k$ & Spring constant for the cantilever $(\mathrm{N} / \mathrm{m})$ \\
\hline$L$ & Length of the cantilever (m) \\
\hline$Q_{f}$ & Quality factor the cantilever oscillations \\
\hline$P_{\mathrm{vdW}}$ & van der Walls pressure force \\
\hline$P_{\mathrm{el}}$ & Electrostatic pressure force \\
\hline $\mathrm{Pt}$ & Total pressure force \\
\hline$R$ & The gas constant $(8.31441 \mathrm{~J} / \mathrm{mol} \mathrm{K})$ \\
\hline$R$ & Particle radius (m) \\
\hline $\mathrm{Ra}$ & Average surface roughness \\
\hline $\operatorname{Re}$ & Reynolds number \\
\hline $\mathrm{Rz}$ & Mean roughness \\
\hline$T$ & Absolute temperature $(\mathrm{K})$ \\
\hline$x$ & Distance between molecules \\
\hline$x$ & Distance from the surface in the double layer $(\mathrm{m})$ \\
\hline$x$ & $\begin{array}{l}\text { Net cantilever deflection in force measurement } \\
\left(x=\left(X-X_{0}\right) / \chi ; \mathrm{m}\right)\end{array}$ \\
\hline$X$ & $\begin{array}{l}\text { Output signal by the photomultiplier for the over- } \\
\text { all bending of the cantilever in force measurement } \\
(\mathrm{mV})\end{array}$ \\
\hline$X_{0}$ & $\begin{array}{l}\text { Output signal by the photomultiplier when two sur- } \\
\text { faces are not interacting }(\mathrm{mV})\end{array}$ \\
\hline$z$ & Valence of the electrolyte \\
\hline$\Gamma_{i}$ & $\begin{array}{l}\text { The imaginary component of the hydrodynamic } \\
\text { function }\end{array}$ \\
\hline$\mu_{f}$ & $\begin{array}{l}\text { Viscosity of fluid in which cantilever vibrates (typi- } \\
\text { cally air; } 1.79 \times 10^{-5} \mathrm{~kg} / \mathrm{m} \mathrm{sec} \text { ) }\end{array}$ \\
\hline$\xi$ & Zeta potential $(\mathrm{mV})$ \\
\hline$\rho$ & Density $\left(\mathrm{kg} / \mathrm{m}^{3}\right)$ \\
\hline$\rho_{f}$ & $\begin{array}{l}\text { Density of fluid in which cantilever vibrates (typi- } \\
\text { cally air; } 1.23 \mathrm{~kg} / \mathrm{m}^{3} \text { ) }\end{array}$ \\
\hline$\omega_{f}$ & $\begin{array}{l}\text { Cantilever's fundamental resonance frequency } \\
\text { (hertz) }\end{array}$ \\
\hline$\psi$ & Measured surface potential (mV) \\
\hline$\psi_{i}$ & Surface potential of particles (V) \\
\hline$\psi_{\text {avg }}$ & AFM measured average surface potential (mV) \\
\hline
\end{tabular}

\section{Materials}

Two atomically smooth planar oxide surfaces (quartz 0001 and saphire 0001 single crystals) were employed as substrates. Properties of these surfaces are presented in Table 1.

Several quartz, silica, alumina and silicon nitride powders were employed to obtain relevant material properties using zeta potential, colloidal titration, particle size distribution and surface area measurements and SEM and XRD analysis. The coding of the samples measured physical properties of the powders are presented in Table 2.
Table 1

Properties of the quartz and sapphire substrates used in the study.

\begin{tabular}{llll}
\hline Substrate & $\begin{array}{l}\text { Physical } \\
\text { properties }\end{array}$ & $\begin{array}{l}\text { Surface } \\
\text { properties }\end{array}$ & Manufacturer \\
\hline Quartz & $\begin{array}{l}\text { Single crystal } \\
1 \mathrm{~cm} \times 1 \mathrm{~cm}\end{array}$ & $\begin{array}{l}0001 \text { Alignment } \\
\mathrm{Ra}=0.109 \mathrm{~nm}\end{array}$ & MTI, CA, USA \\
& & $\mathrm{Rz}=0.123 \mathrm{~nm}$ & \\
& Single crystal & 0001 & MTI, CA, USA \\
Sapphire & $1 \mathrm{~cm} \times 1 \mathrm{~cm}$ & $\begin{array}{l}\text { Alignment } \\
\mathrm{Ra}=0.107 \mathrm{~nm}\end{array}$ & \\
& & $\mathrm{Rz}=0.113 \mathrm{~nm}$ & \\
& & & \\
& & & \\
& & & \\
& &
\end{tabular}

Table 2

Properties of the quartz, silica and alumina powders used in the study.

\begin{tabular}{|c|c|c|}
\hline Powders & Physical properties & Manufacturer \\
\hline Quartz,SO-01 & $\begin{array}{l}d_{90}: 77 \mu \mathrm{m} \\
d_{50}: 37 \mu \mathrm{m} \\
\text { BET: } 1 \mathrm{~m}^{2} / \mathrm{g} \\
\rho: 2.6 \mathrm{~g} / \mathrm{L} \\
\text { Purity: } \geq 95\end{array}$ & $\begin{array}{l}\text { Sigma-Aldrich, } \\
83-340\end{array}$ \\
\hline Quartz, SO-02 & $\begin{array}{l}d_{90}: 96.3 \mu \mathrm{m} \\
d_{50}: 26.3 \mu \mathrm{m} \\
\text { BET: } 1 \mathrm{~m}^{2} / \mathrm{g} \\
\rho: 2.6 \mathrm{~g} / \mathrm{L} \\
\text { Purity: } \geq 95 \%\end{array}$ & Natural Quartz \\
\hline Silica, SO-03 & $\begin{array}{l}d_{90}: 4.9 \mu \mathrm{m} \\
d_{50}: 1.9 \mu \mathrm{m} \\
\text { BET: } 3.17 \mathrm{~m}^{2} / \mathrm{g} \\
\rho: 2.6 \mathrm{~g} / \mathrm{L} \\
\text { Purity: min } 99.8 \%\end{array}$ & $\begin{array}{l}\text { Admatech, Japan } \\
\text { Admafine SO-E6 }\end{array}$ \\
\hline Alumina, AO01 & $\begin{array}{l}d_{90}: 0.3 \mu \mathrm{m} \\
d_{50}: 0.2 \mu \mathrm{m} \\
\text { BET: } 12.3 \mathrm{~m}^{2} / \mathrm{g} \\
\rho: 3.9 \mathrm{~g} / \mathrm{L} \\
\text { Purity: } 99.995 \%\end{array}$ & $\begin{array}{l}\text { Sumitomo, Japan } \\
\text { AKP } 50\end{array}$ \\
\hline Alumina, AO02 & $\begin{array}{l}d_{90}: 2.3 \mu \mathrm{m} \\
d_{50}: 0.7 \mu \mathrm{m} \\
\text { BET: } 3.94 \mathrm{~m}^{2} / \mathrm{g} \\
\rho: 3.9 \mathrm{~g} / \mathrm{L} \\
\text { Purity: prum } \geq 95\end{array}$ & $\begin{array}{l}\text { Alcoa, Germany } \\
\text { CT 3000SG }\end{array}$ \\
\hline Alumina, AO03 & $\begin{array}{l}d_{90}: 2 \mu \mathrm{m} \\
d_{50}: 0.5 \mu \mathrm{m} \\
\text { BET: } 7.34 \mathrm{~m}^{2} / \mathrm{g} \\
\rho: 3.65 \mathrm{~g} / \mathrm{L} \\
\text { Purity: prum } \geq 95\end{array}$ & $\begin{array}{l}\text { Admatech, Japan } \\
\text { Admafine AO-802 }\end{array}$ \\
\hline Silicon nitride, SN & $\begin{array}{l}d_{90}: 20.3 \mu \mathrm{m} \\
d_{50}: 2.6 \mu \mathrm{m} \\
\text { BET: } 1.26 \mathrm{~m}^{2} / \mathrm{g} \\
\rho: 3.44 \mathrm{~g} / \mathrm{L}\end{array}$ & $\begin{array}{l}\text { Sigma Aldrich } \\
24862-2\end{array}$ \\
\hline
\end{tabular}

Rectangular silicon nitride cantilevers (Type ORC-10, Veeco Instrument, CA, USA) were used in the force measurement and employed as charge probes (Fig. 1).

Zeta potential measurements were obtained in $10^{-3} \mathrm{M} \mathrm{KCl}$ solutions at a solid/liquid ratio of $0.1 \mathrm{~g} / \mathrm{L}$ following $30 \mathrm{~min}$ of contact with solution and were periodically checked against a standard solution for accuracy. Results are presented in Fig. 2(a) for quartz and silica, in Fig. 2(b) for alumina and in Fig. 2(1c) for silicon nitride powders. Each symbol in the figures is actually an average of 6 Zeta potential readings. The spread of the zeta potential measurements are shown with associated error bars.

The Hamaker Constants of the interacting bodies which are very important in the analysis of the AFM measurements are presented in Table 3 for the materials used in this study.

\section{Methods}

A Digital Instrument AFM (MMSPM-Nano Scope IV) equipped with a custom-made liquid cell was employed in the force measurements in aqueous media. Due to the very sensitive nature of the work, several procedures had to be developed prior to carrying 
Table 3

Hamaker Constants of the silica, silicon nitride and alumina materials.

\begin{tabular}{|c|c|c|c|c|}
\hline Substrate & Hamaker constant, J & Medium & Method & Source \\
\hline Quartz & $1.02 \times 10^{-20}$ & Water & Full Lifshtiz & Bergström [30] \\
\hline Alumina & $3.67 \times 10^{-20}$ & Water & Full Lifshtiz & Bergström [30] \\
\hline Silicon nitride & $4.85 \times 10^{-20}$ & Water & Full Lifshtiz & Bergström [30] \\
\hline
\end{tabular}

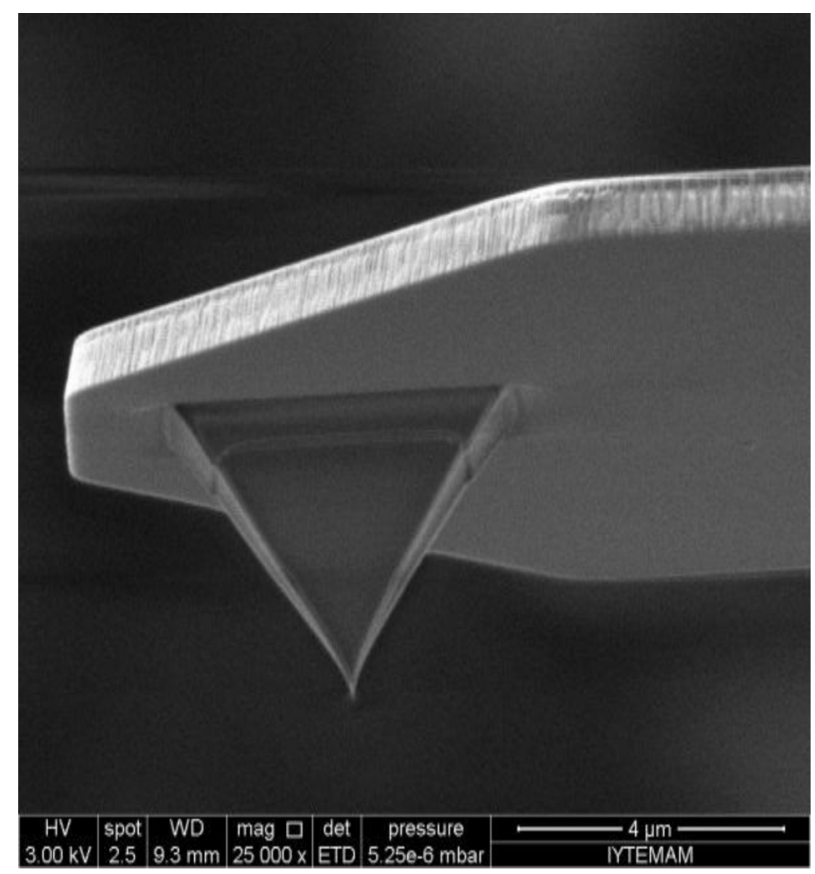

Fig. 1. A view of one of the rectangular silicon nitride cantilevers (Type ORC-10, Veeco Instrument, CA, USA) used in the force measurements.

out accurate, reliable and reproducible force measurements. A brief explanation of these procedures is as follows.

Surface Cleaning: The substrates, the silicon nitride probes and the liquid cell were all subjected to an extensive cleaning procedure before each test. The procedure involved t pre-washing in water and ethanol, treatment with ultrasound, radiation with UV to remove residual surface contaminant, re-washing with ethanol and rinsing with water and finally conditioning for $10 \mathrm{~min}$ in the experimental solution. The total residence time of immersion of the surfaces in the cell was around $30 \mathrm{~min}$ in a typical test.

Determination of Cantilever Spring Constants: Though the manufacturer provides an average spring constant for a batch of cantilevers, the exact spring constant value was required for each cantilever for accurately converting the cantilever signal from the AFM to actual force data. Therefore, individual spring constant of each cantilever $(k)$ was determined using Sader's method [31]. The method involves determining the width $(b)$, length $(L)$, resonant frequency $\left(\omega_{f}\right)$, and $Q$ factor $\left(Q_{f}\right)$ for each cantilever at ambient density $\left(\rho_{f}\right)$ and viscosity $\left(\mu_{f}\right)$. The expression for the spring constant $k$ for rectangular cantilevers is given as:

$k=0.196 \rho_{f} b^{2} L Q_{f} \omega_{f}^{2} \Gamma_{i}\left(\omega_{f}\right)$

$\Gamma_{i}$ in the equation is a complex function of Reynolds number [31] which is given as:

$R e=\frac{\rho_{f} \omega_{f} b^{2}}{4 \mu_{f}}$

The individual spring constants measured for a box of 10 cantilevers are presented in Fig. 3. It can be seen that though the average spring constant for the population of the cantilevers agreed
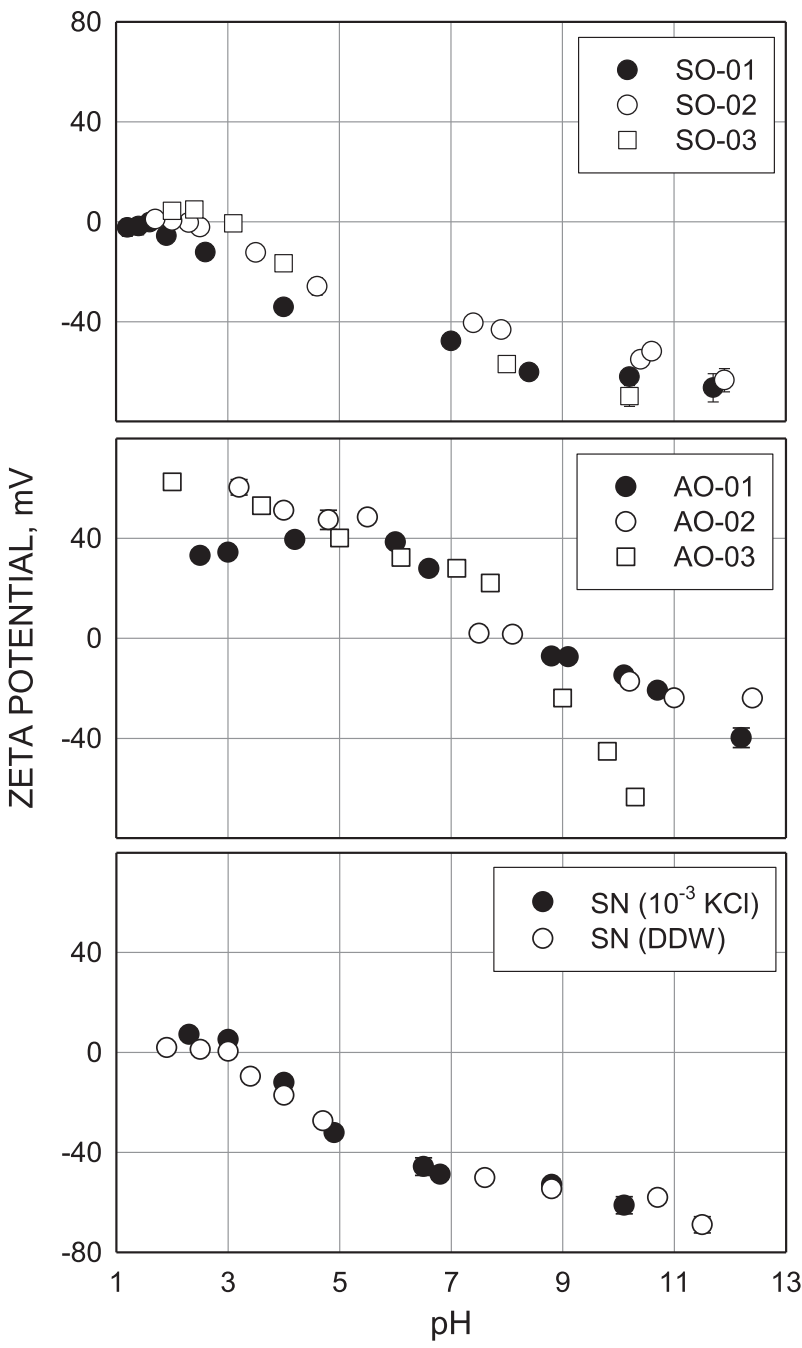

Fig. 2. Results of the zeta potential measurements for quartz/silica, alumina and silicon nitride powders. See Table 2 for coding of the samples. (Those symbols which seem to have no error bars have errors smaller than the symbol size.)

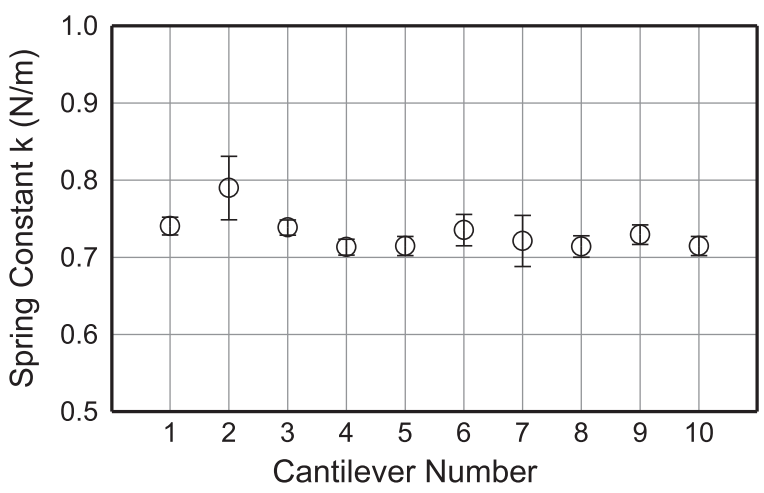

Fig. 3. Measured spring constants $(k)$ of individual cantilevers in a factory package of 10 . (The average $k$ for the box of 10 by the manufacturer is $0.73 \mathrm{~N} / \mathrm{m}$.) 
Piezo Displecement,D (nm)
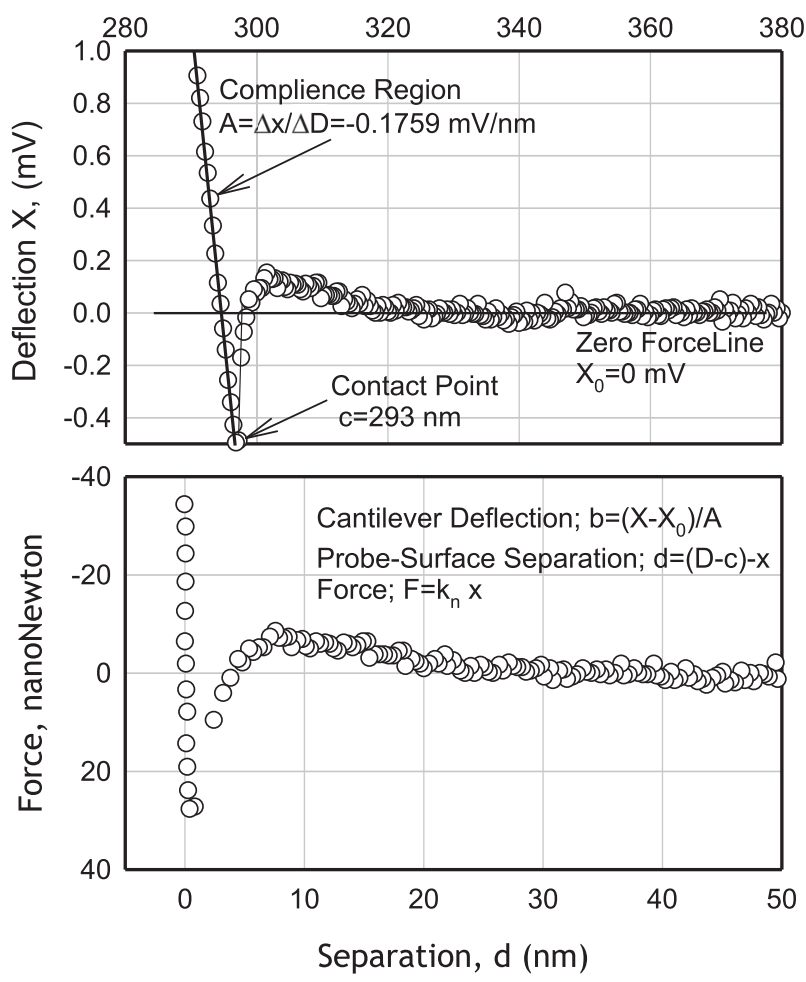

Fig. 4. The raw plot of piezo movement versus cantilever bending for the force measurement at a single point on the substrate (top figure) and the actual force versus probe-to-surface distance curve generated from this data (bottom figure) (adapted from Ref [29]). The raw data is processed using the algorithm shown in the insets.

well with the value provided by the company $(0.73 \mathrm{~N} / \mathrm{m})$, there was a scatter (between 0.713 and 0.790 ) in the spring constants of individual cantilevers, corresponding to an error of about $5.5 \%$.

Obtaining Force-Distance Curves: The force measurement at a single point on the substrate results in a raw plot of piezo movement versus cantilever bending (Fig. 4(a)). The piezo movement is directly provided by the AFM in nanometers whereas the bending is an output signal in millivolts by the photomultiplier measuring the position of the laser light falling on the. detector The raw data can be converted to actual force versus probe-to-surface distance curve (Fig. 4(b)) using a proper algorithm shown as inset in the figure (see also [29] for details).

Calculation of Theoretical Curves: The force per area for two interacting plates (pressure force in Pascal) due to the van der Waals component $\left(P_{v d W}\right)$ as a function of plate separation $h$ as:

$P_{v d W}(h)=\frac{A_{132}}{6 \pi h^{3}}$

where $A_{123}$ is the Hamaker constant between the substrate 1 and substrate 2 separated by electrolyte solution 3 .

The corresponding electrostatic pressure force $\left(P_{e l}\right)$ between two surfaces can be obtained by solving the Poisson-Boltzmann distribution in one dimension. Though analytical expressions for electrostatic pressure force are available, they are valid only for weak charging conditions. For highly-charged systems, usually numerical procedures are employed. In this work, a recent analytical solution of the Poisson-Boltzmann equation was employed to determine the electrostatic pressure force between two substrates [32]. The solution which allows analytical analysis of charge and potential regulated surfaces shows perfect agreement with

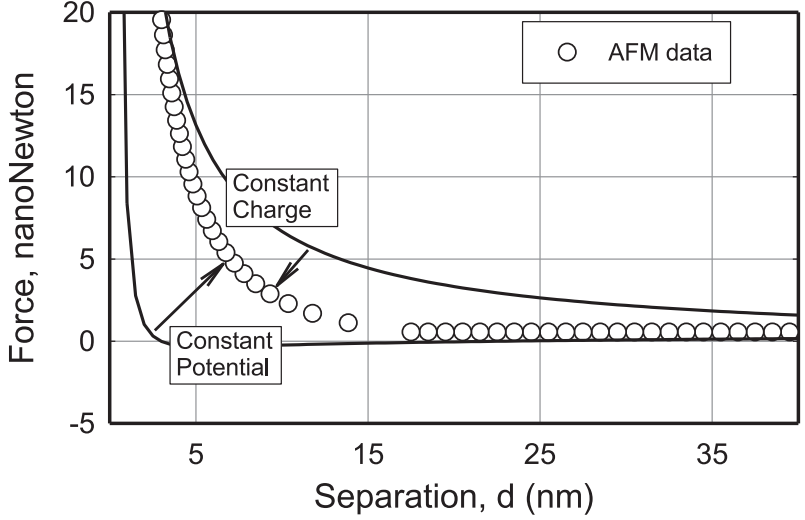

Fig. 5. Force-distance data $\left(F_{A F M}\right)$ obtained at with silicon nitride tip on silica at $\mathrm{pH} 10$ and $10^{-3} \mathrm{M} \mathrm{KCl}$. The solid lines give the first-guess curves for theoretical force-distance curves for constant potential and constant charge conditions. The parameters kept constant obtaining the theoretical force-distance curves: $\psi_{\mathrm{Si} 3 \mathrm{~N} 4}=-60 \mathrm{mV} ; R=6 \mathrm{~nm} ; k=0.76 \mathrm{~N} / \mathrm{m}, A_{132}=2.0710^{-20} \mathrm{~J} ; C_{0}=10^{-3} \mathrm{M} \mathrm{KCl} ; z=1: 1 ;$ $T=293.15 \mathrm{~K})$. The parameter varied in adjusting the theoretical lines: $\psi_{\mathrm{SiO} 2}$.

numerical results for all levels of charging conditions under various charging regimes (constant potential and constant charge surfaces).

If the conditions in the force measurement were selected such that the DLVO theory is applicable, the overall pressure force per unit area of the interacting plates $\left(P_{t}\right)$ can be taken as a sum of the van der Waals and electrostatic pressure forces $\left(P_{t}=P_{v d W}+P_{e l}\right)$.

A comparison of this theoretical total pressure force $\left(P_{t}\right)$ with the actual force measured in AFM ( $F_{A F M}$ in Newtons) requires that the theoretical pressure curve (between two surfaces) must be converted to a force curve $\left(F_{t}\right)$ (between a surface and a spherical particle) using the Derjaguin method [33-36]:

$F_{t}=2 \pi R \int_{x}^{\infty} P_{t}(h) d h$

In this equation, $R$ is the radius of the probe and $h$ is the distance between the tip of the particle and the substrate.

Estimation of Surface Potential from a Comparison of $F_{t}$ and $F_{A F M}$ : An illustrative actual force-distance curve obtained from the AFM for the silica substrate and silicon nitride tip $\left(F_{A F M}\right)$ is given in Fig. 5 as symbols. The first-guesses of the theoretical force-distance curves $\left(F_{t}\right)$ for the data are also presented in the figure as solid lines for constant potential and constant charge conditions. The parameters which are kept constant for generating the theoretical curves are given below the figure. It should be noted that the only parameter varied for approaching the theoretical curves to the actual force curve was the surface potential of silica, $\Psi_{\mathrm{SiO}_{2}} \psi_{\mathrm{SiO} 2}$.

The procedure outlined above was repeated until a best fit line was obtained for the force-distance data which yielded the bestestimate surface potential for the surface for that measurement. Then, the procedure was repeated on multiple points on the surface as follows: Initially five boxes with dimensions of $1 \mu \mathrm{m} \times 1 \mu \mathrm{m}$ were selected on a $5 \mu \mathrm{m} \times 5 \mu \mathrm{m}$ area on the surface, four in corners and one in the middle. On each box, force measurements were carried out on nine point locations separated by $400 \mathrm{~nm}$. Each of these nine measurements at a given point was repeated thrice to ensure reproducibility. This data was then used to obtain the potential contours of the surface.

\section{Results and discussion}

AFM force measurements were carried out in the liquid cell of the AFM using the cleaning and data acquisition and processing procedures outlined above. The electrolyte solution strength was kept constant in all experiments at $10^{-3} \mathrm{M} \mathrm{KCl}$. 


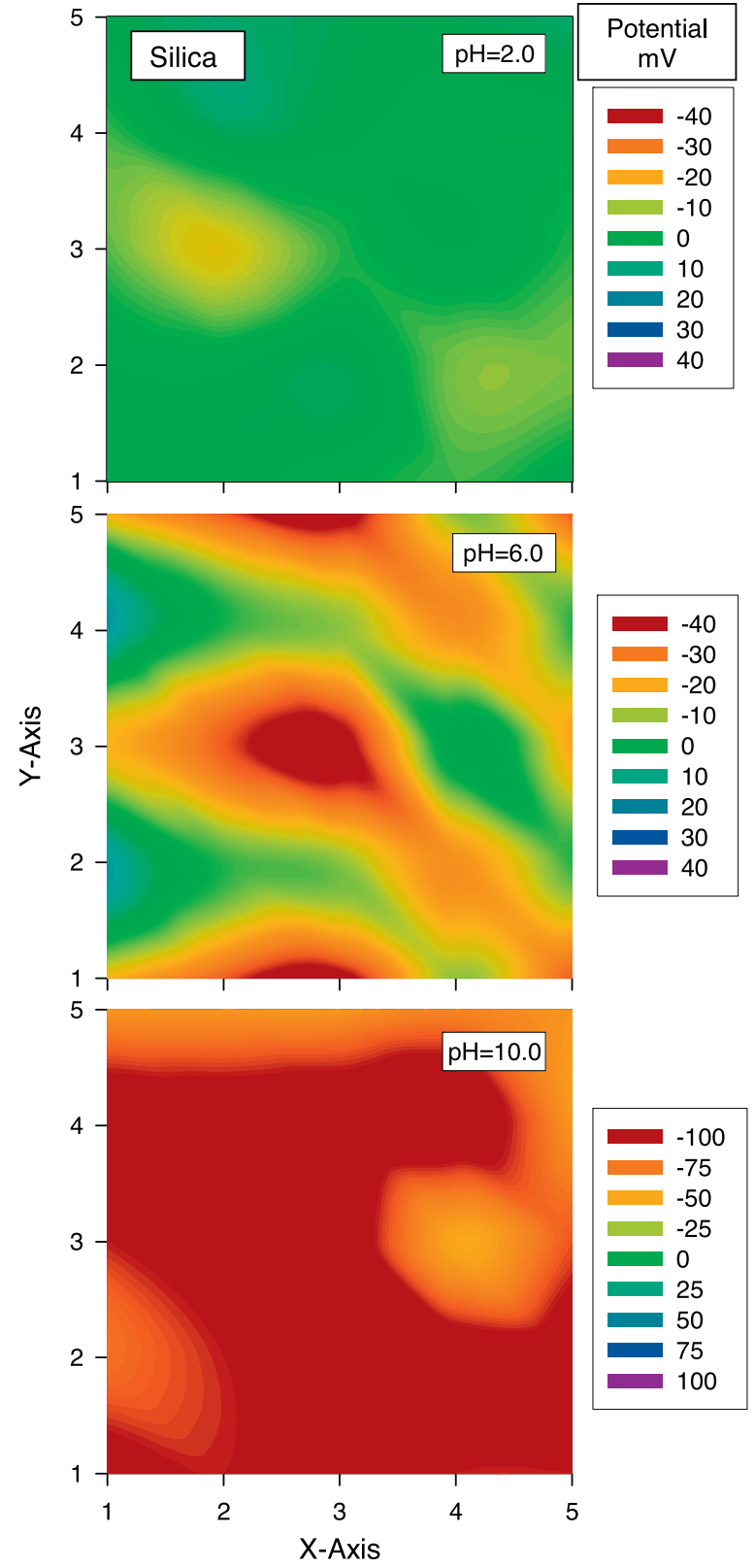

Fig. 6. Surface potential distributions on a $5 \mu \mathrm{m} \times 5 \mu \mathrm{m}$ portion of the quartz (0001) surface at various pH values in $10^{-3} \mathrm{M} \mathrm{KCl}$ solution.

Measurements were carried out for two well-defined substrates (silica and alumina single crystals) at three different $\mathrm{pH}$ values of 2, 6, 10. The results are presented in Fig. 6 for silica and Fig. 7 for alumina substrates. The parameters related to these figures are presented in Table 4. Table also shows the numerical values of the surface potentials and the potential ranges observed on the quartz and sapphire surfaces.

It can be seen from Fig. 6 and Table 4 that the quartz surface has an average surface potential of $0 \mathrm{mV}$ at $\mathrm{pH} 2$. However this potential is not evenly distributed on the surface. The potentials on quartz substrate vary between $-10 \mathrm{mV}$ and $+10 \mathrm{mV}$. At $\mathrm{pH} 6$, the quartz surface seems to be becoming more negative with surface potentials changing between 0 and $-40 \mathrm{mV}$. The average surface potential for $\mathrm{pH} 6$ is $-30 \mathrm{mV}$. When $\mathrm{pH}$ is increased to 10 , the quartz surface becomes dominantly negative. In this case, the surface potentials vary between -80 and $-100 \mathrm{mV}$ while the average surface potential drops to $-90 \mathrm{mV}$.
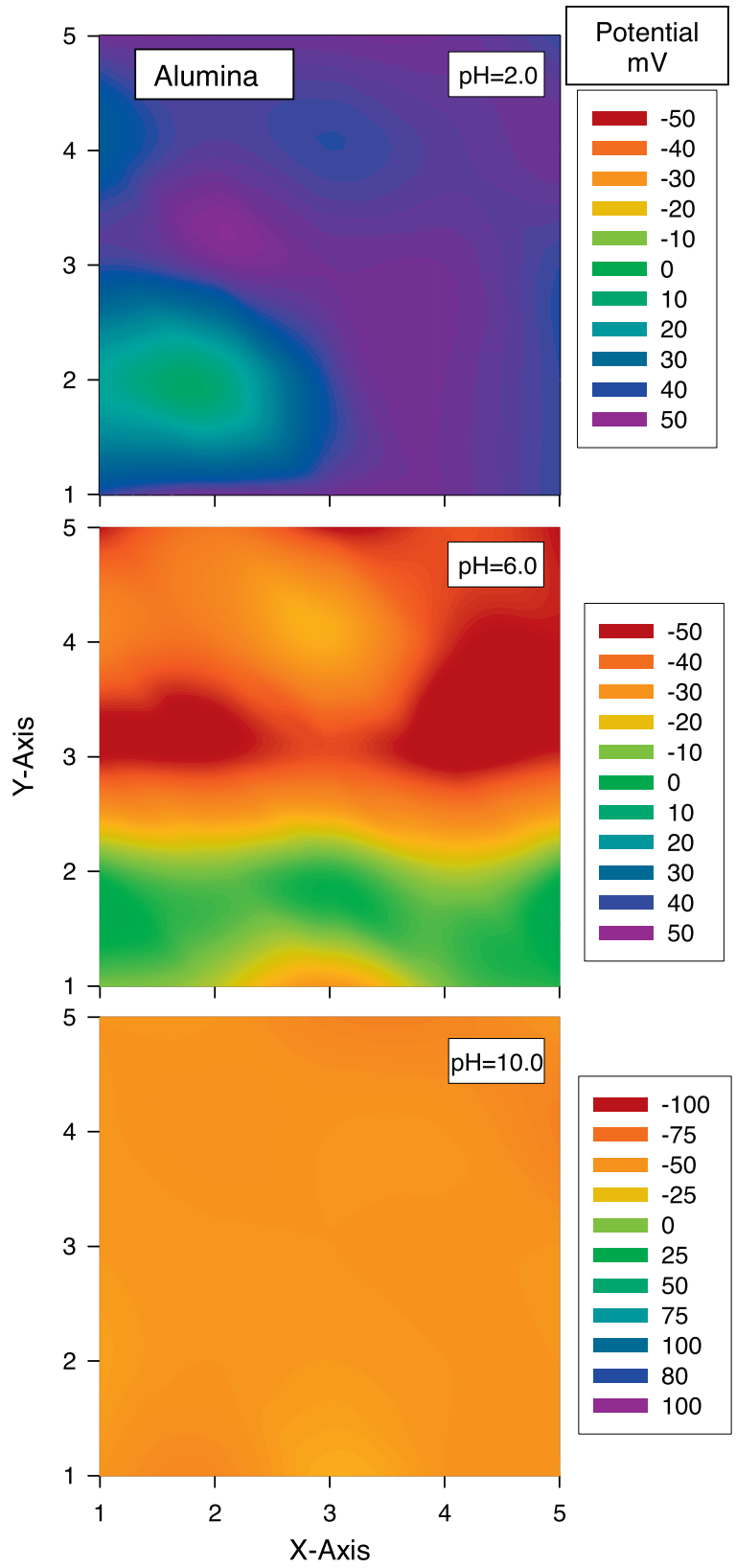

Fig. 7. Surface potential distributions on a $5 \mu \mathrm{m} \times 5 \mu \mathrm{m}$ portion of the sapphire $(0001)$ surface at various $\mathrm{pH}$ values in $10^{-3} \mathrm{M} \mathrm{KCl}$ solution.

For the sapphire substrate, the surface is predominantly positive at a $\mathrm{pH}$ of 2 with an average surface potential of $+40 \mathrm{mV}$ with a range between +30 and $+45 \mathrm{mV}$. The sapphire surface loses this positive potential significantly when the $\mathrm{pH}$ is increased to 6 . The average surface potential is $-30 \mathrm{mV}$ in this case with a spread of the potentials between -10 and $-40 \mathrm{mV}$. The surface becomes negatively charged at $\mathrm{pH} 10$ such that the average surface potential drops to $-60 \mathrm{mV}$. The sapphire surface at this $\mathrm{pH}$ shows a distribution of potentials between -50 and $-65 \mathrm{mV}$.

In Fig. 8, the average surface potentials with error bars on the quartz surface obtained from the contour graphs (Fig. 6) are plotted against the electrophoretic data obtained for the silica and quartz powders. It can be seen that the average surface potentials obtained for the quartz surface (filled circles) at different solution $\mathrm{pH}$ agree quite well with the zeta potential data, especially at the acidic range. There seems to be a disagreement between the zeta potentials and the average surface potential of the quartz surface at $\mathrm{pH}$ 
Table 4

Experimental Parameters, average potentials and potential ranges for the silica and sapphire surfaces.

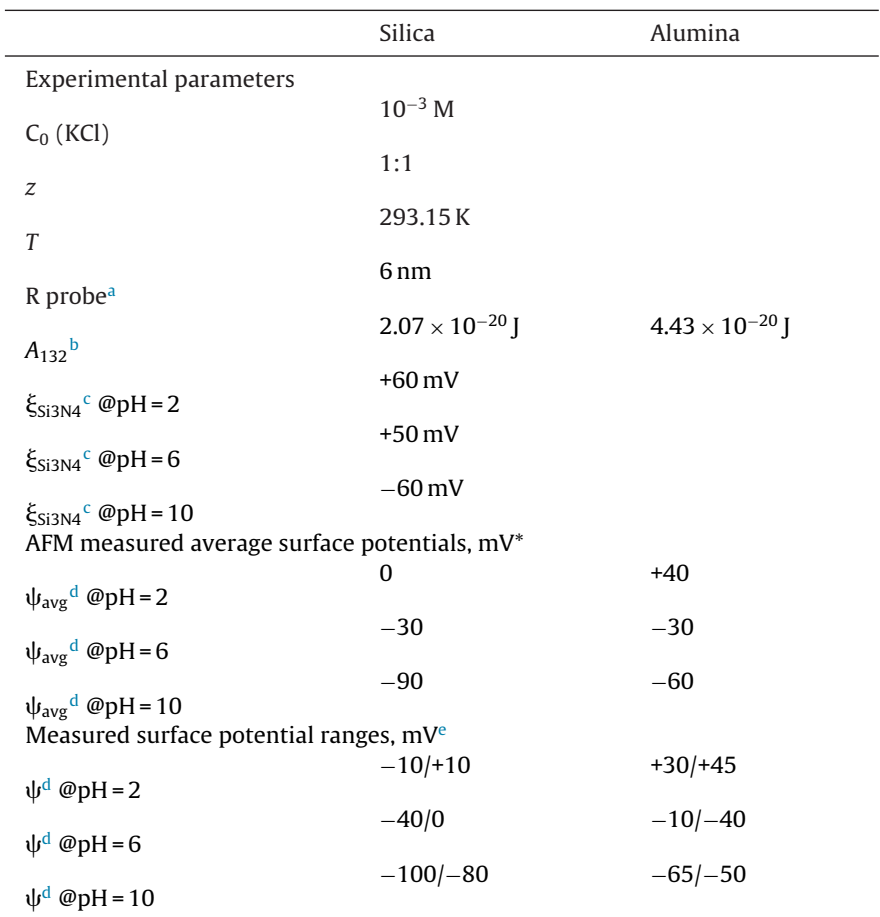

a Measured radius of the $\mathrm{Si}_{3} \mathrm{~N}_{4}$ probe using SEM.

b From Bergstrom [30].

c Measured using zeta sizer Model Malvern Nano-Zs.

d Average potentials obtained from the potentials measured by AFM on 45 separate locations on the silica and sapphire substrates (see also Figs. 6 and 7).

e Potential ranges for the averages given in d above (see also Figs. 6 and 7).

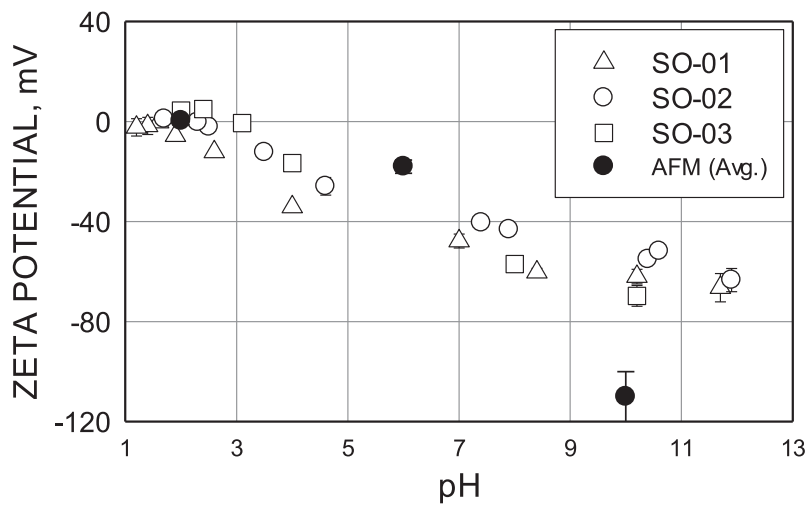

Fig. 8. A comparison of the zeta potential measurements for the quartz/silica powders (open symbols-reproduced from Fig. 2) with the surface-averaged AFM potential measurement obtained on a quartz single crystal surface (filled symbolsobtained from Fig. 6).

10. This disagreement can be explained by the possible hydration of the surface at this high $\mathrm{pH}$. Polat et al. [29] observed previously that a hydrated surface layer which may develop at high $\mathrm{pH}$ values can act as a physical barrier during the approach of the surfaces. Under these conditions authors stated that use of the DLVO theory may not be applicable.

In Fig. 9, the average surface potentials for the sapphire surface obtained from the contour graphs of Fig. 7 are plotted against the zeta potentials for various alumina powders. It can be seen that the average surface potentials obtained for the sapphire surface (filled circles) at different solution $\mathrm{pH}$ seem to be lower than the measured zeta potentials at all $\mathrm{pH}$ values such that the point of zero charge is

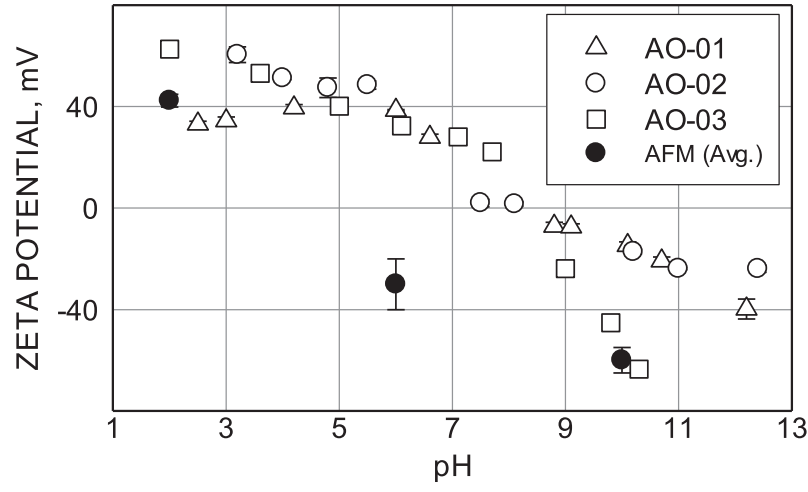

Fig. 9. A comparison of the zeta potential measurements for the alumina powders (open symbols-reproduced from Fig. 2) with the surface-averaged AFM potential measurement obtained on a single crystal surface (filled symbols-obtained from Fig. 7).

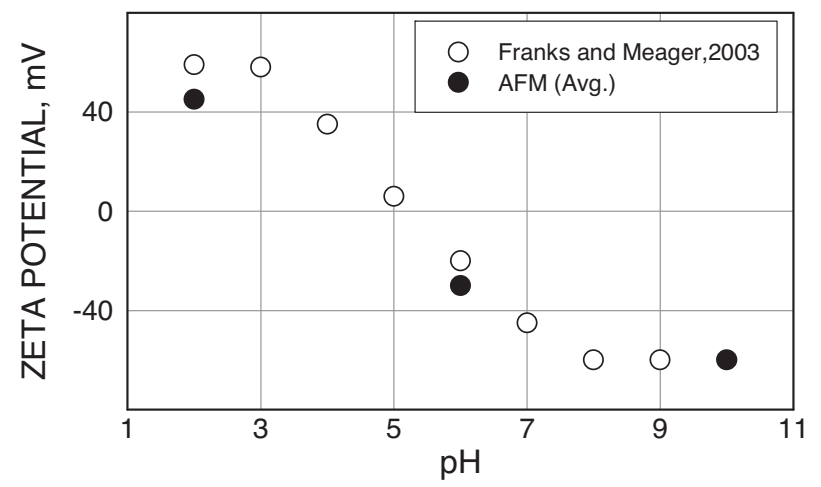

Fig. 10. Surface potential of 0001 sapphire single crystal as a function of $\mathrm{pH}$ from streaming potential from Franks and Meager [26] (open circles) and from the AFM measurements in this work (filled circles-reproduced from Fig. 9).

around 5.2 for the sapphire surface as opposed to the point of zero charge of around 8.5 for the powders.

Using a streaming potential technique, Franks and Meagher [26] observed that single crystal sapphire (0001) surface showed a point of zero charge of 5.2. The streaming potential data obtained by these authors are plotted against the AFM-measured surface potentials presented in Fig. 10 for the sapphire surface. It can be seen that the streaming potential values of the sapphire surface agrees quite well with the surface averages of the potential values determined by the methods developed in this paper using the AFM as a charge probe.

\section{Conclusions}

In this work, we employed atomic force microscopy to determine the surface potentials on various locations on selected metal oxide surfaces in aqueous solutions in order to estimate the potential distribution of the surface in form of a potential map.

The method is based on measuring the interaction forces between the AFM tip and a desired surface at multiple points and correlating the measured force with the DLVO theory to predict the surface potential at each point. This use of the AFM is novel but requires very careful experimental design and careful use of available theories.

The results presented in this work demonstrate that within the bounds of the applied theory the surface potential distributions predicted with the AFM agree quite well with the data from other independent electrophoretic measurements. 


\section{Acknowledgement}

The support from The Scientific and Technological Research Council of Turkey (TUBITAK) under the project grant TUBITAK 109 T695 is acknowledged.

\section{References}

[1] B.V. Derjaguin, L. Landau, Physicochim. URSS 14 (1941) 633.

[2] E.J.W. Verwey, J.T.G. Overbeek, Theory and Stability of Lyophobic Colloids, Elsevier, Amsterdam, 1948.

[3] E.M.V. Hoek, G.K. Agarwal, J. Colloid Interface Sci. 298 (2006) 50.

[4] M. Boström, V. Deniz, G.V. Franks, B.W. Ninham, Adv. Colloid Interface Sci. 123-126 (2006) 5

[5] J.A. Brant, A.E. Childress, Environ. Eng. Sci. 19 (2002) 413.

[6] G. Binnig, C.F. Quate, Ch. Gerber, Phys. Rev. Lett. 56 (1986) 930.

[7] W.A. Ducker, T.J. Senden, R.M. Pashley, Nature 353 (1991) 239.

[8] H. Butt, Biophys. J. 60 (1991) 1438.

[9] I. Larson, C.J. Drummond, D.Y.C. Chart, F. Grieser, Langmuir 13 (1997) 2109.

[10] A.M. Freitas, M.M. Sharma, J. Colloid Interface Sci. 233 (2001) 73.

11] S.W. Lee, W. Sigmund, J. Colloid Interface Sci. 243 (2001) 365.

[12] S.W. Lee, W. Sigmund, Colloids and Surfaces A, Physicpchem. Eng. Aspects 204 (2002) 43

[13] J. Drelich, J. Long, J. Colloid Interface Sci. 303 (2006) 627.

[14] W.A. Ducker, T.J. Senden, R.M. Pashley, Langmuir 8 (1992) 1831.

[15] S.R. Biggs, P. Mulvaney, C.F. Zukoski, F. Grieser, J. Am.Chem. Soc. 116 (1994) 9150.
[16] G. Toikka, R. Hayes, J.J. Ralston, Colloids Surf. A: Physicpchem. Eng. Aspects 141 (1998) 3

[17] I. Larson, C.J. Drummond, D.Y.C. Chan, F. Grieser, J. Am. Chem. Soc. 115 (1993) 11885.

[18] I. Larson, C.J. Drummond, D.Y.C. Chan, F. Grieser, J. Am. Chem. Soc. 99 (1995) 2114.

[19] S.R. Biggs, Langmuir 11 (1995) 156

[20] M.S. Hook, P.G. Hartley, P.J. Thistlethwaite, Langmuir 15 (1999) 6220.

[21] G.H. Pedersen, L. Bergstrom, Acta Mater. 48 (2000) 4563.

[22] G. Toikka, R. Hayes, J. Ralston, Colloid Interface Sci. 180 (1996) 339

[23] A. Kauppi, K.M. Andersson, L. Bergstrom, Cem. Concr. Res. 35 (2005) 133.

[24] M.E. Karaman, R.M. Pashley, Colloid Interface Sci. 129-130 (1997) 239

[25] L. Meagher, G.V. Franks, M.L. Gee, J. Scales, Colloids Surf. A: Physicpchem. Eng. Aspects 146 (1999) 123.

[26] G.V. Franks, L. Meagher, Colloids Surf. A: Physicpchem. Eng. Aspects 214 (2003) 99.

[27] U. Nowostawska, S.G. Sander, K.A. Hunter, Colloids Surf. A: Physicpchem. Eng. Aspects 266 (2005) 200.

[28] Y. Gan, G.V. Franks, Langmuir 22 (2006) 6087

[29] M. Polat, K. Sato, T. Nagaoka, K. Watari, J. Colloid Interface Sci. 304 (2006) 378

[30] L. Bergström, Adv. Colloid Interface Sci. 70 (1997) 125

[31] J.E. Sader, J.W.M. Chon, P. Mulvaney, Rev. Sci. Instrum. 70 (1999) 3967.

[32] M. Polat, H. Polat, J. Colloid Interface Sci. 341 (2010) 178.

[33] B.V. Derjaguin, Kolloid. Zh. 69 (1934) 155.

[34] S. Bhattacharjee, M. Elimelech, J. Colloid Interface Sci. 193 (1997) 273.

[35] S. Bhattacharjee, J. Chen, M. Elimelech, Colloids Surf. 165 (2000) 143.

[36] H.J. Butt, M. Kappl, Surface and Interfacial Forces, WILEY-VCH Verlag GmbH, Weinheim, 2010 